\title{
A privacidade da miniatura: uma pesquisa em cotidiano escolar
}

\section{Privacy of miniatures: research in school daily life}

\author{
Mitsi Pinheiro de Lacerda ${ }^{1}$
}

\begin{abstract}
RESUMO
Dentre os inúmeros movimentos que se processam na escola, este texto se aproxima de alguns empreendidos pelos estudantes, buscando compreender a tessitura daquilo que produzem silenciosamente. Em meio a observações realizadas em cotidiano escolar e a partir das proposições de Certeau, convida a desconfiarmos daquilo que se mostra aparentemente repetitivo, rotineiro e pouco significativo, buscando compreender e aprender com as lógicas ali presentes. Considerando o cotidiano escolar enquanto espaço de pequenas dimensões que não reproduz a sociedade (mas que a contém), trata-o enquanto miniatura que preserva sua privacidade devido ao desconhecimento sobre o que ali é praticado. Conclui afirmando que o conhecimento sobre a escola precisa aproximar aspectos universais que a organizam, de movimentos perceptíveis no detalhe, nos diferentes usos que lhe conferem os praticantes.

Palavras-chave: cotidiano escolar; organização discente; organização escolar.
\end{abstract}

\begin{abstract}
Among the countless movements that are prosecuted in the school, this text is brought near of someone undertaken by the students, looking to understand the network of what they produce silently. Amid observations carried out in school daily life and from the propositions of Certeau, it invites when we have feeling what appears apparently repetitive, routine and not much
\end{abstract}

1 Doutora em Educação pela Universidade de São Paulo (USP). Professora Adjunta da Universidade Federal Fluminense (UFF). Departamento de Educação Matemática. 
significant, looking to understand and to learn with the logical ones there present. Considering the school daily life while space of small dimensions that does not reproduce the society (but what contains it), treats it while miniature that preserves his privacy due to the ignorance on which there it is practiced. It concludes affirming that the knowledge about school need bringing near universal aspects that organize it, of perceptible movements in the detail, in the different uses that give him the apprentices.

Key-words: school daily life; learning organization; school organization.

\section{Introdução}

A escola é uma organização articulada a um sistema e dispõe de ordenações que incidem sobre a enturmação dos estudantes, os horários, os currículos e quaisquer outros fatores que pretendam gerenciar com economia e eficácia as pessoas e sua produtividade. Em certos aspectos esta organização é marcada pela visibilidade, demarcando o lugar segundo condições que se reproduzem em várias instituições. Sem muita dificuldade podemos distinguir as salas de aulas, as carteiras enfileiradas, a delimitação de posições, as filas dos alunos, o ensino frontal.

Essa organização é familiar aos estudantes, antes mesmo de ingressarem na escola. A inserção de uma determinada ordem institucionaliza o lugar, compreendido enquanto configuração de posições marcada pela estabilidade (CERTEAU, 1994). Disso resulta universalizarmos a compreensão que dispomos acerca da escola, descrevendo, sem muita dificuldade, como se encontra circunscrito o lugar.

A delimitação do lugar é marcada pela visibilidade, regularidade e repetição, que se traduzem em familiaridade para o observador que o toma naquilo que é comum e estável. Tomar a escola somente enquanto lugar onde se encontram dispostos elementos necessários às atividades ali desenvolvidas é algo que dificulta compreender que, embora se assemelhem, em todas as escolas são produzidas distinções.

Para Certeau (1994, p. 203), "os relatos efetuam portanto um trabalho que, incessantemente, transforma lugares em espaços ou espaços em lugares”. Sendo assim, um lugar pode se mostrar enquanto espaço se considerados os deslocamentos, interações, eventos e narrativas presentes. Se junto à descrição sobre onde se encontram posicionados os elementos pudermos narrar os movimentos, colisões e intencionalidades, a escola não se mostrará apenas como 
uma imagem inerte.

Dentre os inúmeros movimentos que se processam na escola, neste texto me aproximo daqueles empreendidos pelos estudantes. Melhor dizendo, busco compreender, a partir das proposições de Certeau, a tessitura do cotidiano escolar tomando como referência o que é produzido tacitamente pelos alunos. Para isso, foi necessário considerar que o “espaço praticado” pelos estudantes dispõe de pelo menos uma característica interessante: sua visibilidade demanda certas disposições do observador para que não se converta em seu contrário, tornando-se invisível. Um espaço aqui tomado como miniatura, no sentido que lhe confere o dicionário - uma “obra de arte delicada e de pequenas dimensões”. Um espaço que não reproduz a sociedade mas que a contém, promovendo a mágica de subverter a posição hegemônica do maior em relação ao menor. No cotidiano escolar não são reproduzidos os problemas que afetam a sociedade, a escola não é uma macrofotografia do que se passa no mundo. Porém, não obstante sua reduzida dimensão, tais problemas estão também contidos nela.

\section{O que já estava ali, e de repente eu vi?}

Neste texto apresento algumas observações realizadas em cotidiano escolar, convidando a tomarmos com um quê de desconfiança aquilo que se mostra aparentemente repetitivo, rotineiro e pouco significativo, buscando compreender e, principalmente, aprender com as lógicas ali presentes.

Eu estava de volta à escola pública onde estudara há vinte e cinco anos, agora como professora e pesquisadora. Sem qualquer dificuldade poderia descrever o que havia se modificado, afinal, como aluna, tivera a oportunidade de conhecer aquele lugar. Em meio a encantamentos, lembranças e nostalgia, muitas novidades me surpreenderam, mas nada me causou tanto estranhamento quanto o fato de observar que os estudantes não se separavam de suas mochilas.

Durante o intervalo para o recreio, e às vezes até mesmo durante uma ida ao banheiro, os estudantes mantinham suas mochilas nas costas. Quando precisavam se distanciar das mesmas, ajeitavam alguém a quem pudessem confiar a vigilância de seus pertences. Para quem um dia havia corrido livremente por aqueles jardins, não poderia passar despercebida a visão de cerca de quatrocentos estudantes se locomovendo com suas mochilas nas costas.

Se deixar a mochila na sala, os caras catam as coisas da gente - foi a explicação que me ofereceram. Muito me entristeceu constatar que o tempo havia passado, as coisas se modificado, a insegurança se instalado. E, sendo assim, 
este caso poderia acabar aqui, integrando as denúncias de atos de violência que assolam as escolas. Poderia acabar aqui, se eu não continuasse achando tudo isso muito estranho. Assim, caminhando no interior da escola, protegidos pelos muros, cadeados e vigilantes, os alunos mantinham junto de si seus pertences. Era assim, no interior da escola. Do lado de fora, contudo, a coisa era diferente.

Do lado de fora, e exatamente a partir do lugar de onde começa o lado de dentro, os alunos e suas mochilas podiam ser vistos de outra forma. Começando no portão de entrada e crescendo continuamente pelo pátio externo enquanto houvesse aluno por chegar, diariamente era organizada uma fila de mochilas. Os estudantes chegavam à escola e, naqueles momentos deliciosos que cada um de nós vivenciamos antes do início das aulas, depositavam suas mochilas no chão e iam se distrair com brincadeiras e conversas.

Ou não. Caso preferisse, o aluno permanecia na fila, mas sua presença física não implicava no direito de se posicionar à frente das mochilas. Ali era demarcado um lugar: sendo gente, sendo mochila, todos obedeciam à ordem de chegada produzindo uma fila que se alternava entre pessoas e coisas. A mesma mochila que dentro da escola permanecia sob a guarda permanente de seu proprietário, ali, do lado de fora, era depositada no chão, em uma fila honesta, silenciosa e organizada.

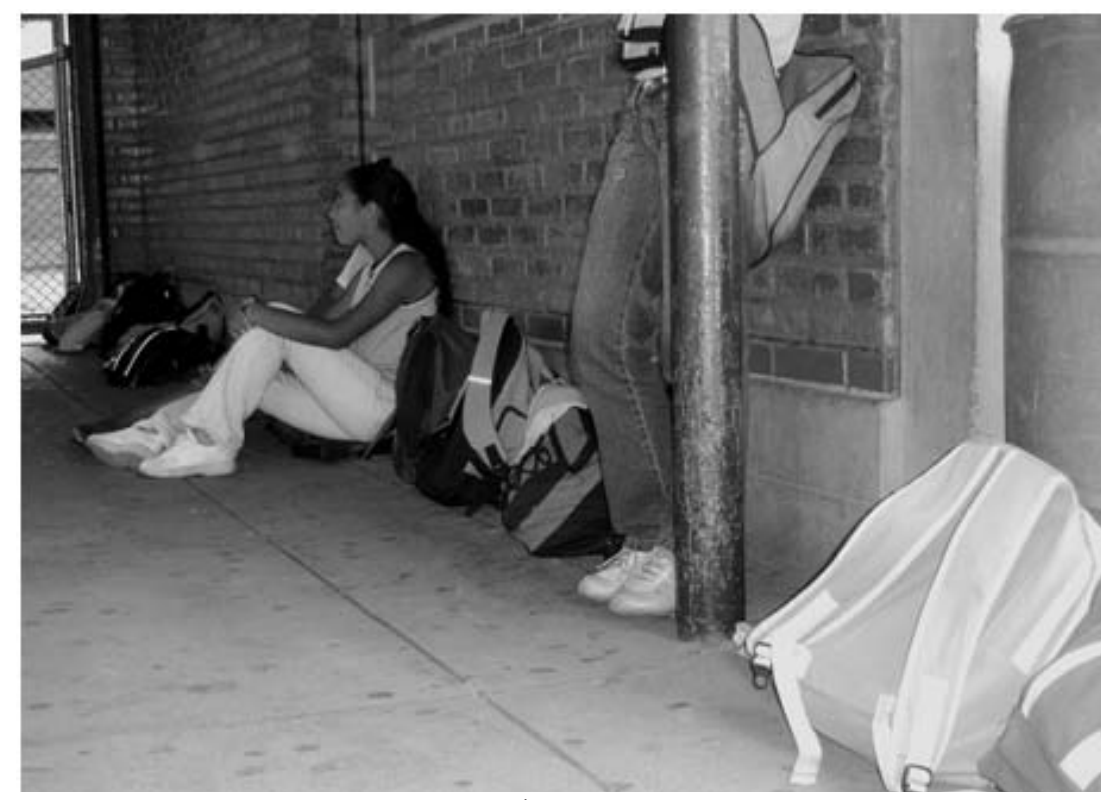

FIGURA 1 - A FILA DE MOCHILAS NO PÁTIO EXTERNO DA ESCOLA 
Organizada. Penso que esta característica provocou ainda mais meu encantamento, me levando a perceber que, para compreender o que se passava, não deveria olhar para as mochilas de forma simplificadora. Não poderia tentar compreender a mochila-nas-costas e a mochila-na-fila do mesmo modo que um etólogo estuda os padrões de comportamento das espécies. O caso das mochilas não se referia a um comportamento coletivo - tratava-se de uma questão de organização.

A compreensão acerca da organização da fila de mochilas não poderia se limitar a uma explicação sobre esta fila. Explicações, aliás, não faltaram. Fazem a fila para entrar primeiro na escola, me disseram. Competem entre si, são muito competitivos, disseram também. Cada vez mais a situação se autoexplicava e se autossimplificava, provocando, por oposição, a desconfiança de que nada pode ser tão óbvio assim.

Era preciso compreender as tramas que teciam aquela organização, mas antes disso era preciso compreender a própria noção de organização. Nesse momento, foi Morin quem me ajudou afirmando que "o princípio de explicação da ciência clássica não concebia a organização enquanto tal. Reconheciam-se organizações (sistema solar, organismos vivos) mas não o problema da organização" (1999, p. 29). Reconhecer organizações referia-se a descrevê-las e, quando muito, a inventar uma explicação suficientemente razoável para justificá-las a partir do ponto de vista de quem explica. Diferente disso, compreender a problemática da organização é algo que exige que as percepções de quem se entrega a esta tarefa se aproximem da pluralidade de significados atribuídos por quem participa, produz e é produzido por aquilo que deseja compreender.

Dentro da escola, onde quase tudo é organizado segundo princípios institucionais, com horários, limites e suas respectivas regras, as crianças não se separavam de suas mochilas. Do lado de fora, antes do sinal da entrada, antes do começo, antes de se submeterem aos cuidados institucionais, as mochilas eram depositadas em uma fila e ali ficavam, sem qualquer vigilância.

Nunca se soube de uma assembleia estudantil que objetivasse a análise e aprovação de um estatuto que contivesse, em um de seus artigos, as disposições que regem a organização de uma fila de mochilas. Não obstante isso, todas as crianças daquela escola pareciam conhecer, tacitamente, tais disposições. Todas conheciam, todas obedeciam. Eram disposições criadas por elas, embora não tenham sido formalmente elaboradas. Disposições aceitas por elas, embora não tenham sido submetidas à aprovação. Disposições que se encarnavam no cotidiano escolar e, assim, como tantas outras, perpassavam diferentes formas que as crianças inventam para se organizar no plano coletivo com muito sucesso, camaradagem e ordem.

Ordem. Eis aqui outra palavra convidativa, recorrente à noção de organi- 
zação. Palavra que necessita tomar como recursivo o seu oposto, a desordem. E para que possam ser compreendidas - ordem, desordem e organização - é necessário ainda que juntemos a isso a interação. São essas as quatro noções que constituem o "tetragrama de Morin", as quais se implicam mutuamente e informam, umas às outras, formas não convencionais de compreensão do mundo. Esse tetragrama, embora não disponha da capacidade de desvendar o que é complexo, contribui para que possamos imprimir mobilidade àquilo que nos dispomos a compreender, nos distanciando de formulações deterministas e simplificadoras.

Para Morin, é preciso olhar para o mundo empregando a dialogia entre estes quatro termos - ordem, desordem, organização e interação. Nada dispõe de uma ordem única e nada é completamente desordenado: ordem e desordem são recursivas e a percepção sobre elas depende, necessariamente, da concepção de organização de quem as constitui - organização que se dá por meio de interações entre as pessoas. Interagindo entre si, as pessoas tecem diferentes relações que se afiguram enquanto organizações às vezes ordenadas e outras vezes desordenadas para um observador externo. Para compreender a ordem de uma organização qualquer, é preciso compreender os significados da desordem que favorecem as interações entre os sujeitos.

Dentro da escola as mochilas precisavam de uma vigília permanente. Fora da escola as mochilas eram depositadas displicentemente e ordenadamente no chão. As mesmas mochilas, os mesmos alunos, a mesma escola. O mesmo espaçotempo, os mesmos sujeitos. Tudo era igual e percebido de formas diferentes, ao mesmo tempo. Talvez aí resida meu estranhamento: herdeira de uma forma cartesiana de olhar para o mundo, não conseguia desvelar esta contradição.

O que justificava essa fila? Por que marcavam sua posição para serem os primeiros a entrarem na escola? Bom... a fila "de entrada" não servia tão somente para entrar, mas, principalmente... para sair! Quem entra primeiro na escola deposita sua caderneta escolar por baixo da pilha de cadernetas que vai se avolumando, as quais, quando são carimbadas, promovem a mágica de levar a caderneta que estava por baixo, para cima. Quem entra primeiro na escola e coloca sua caderneta por baixo de todas as outras, é justamente quem a recebe mais rapidamente quando é chegada a hora de ir. A fila de mochilas não garante somente o primeiro lugar na fila, garante também sair da escola antes de todos. A fila de entrada serve, ao mesmo tempo, para entrar e sair da escola em primeiro lugar.

Essa recursividade entre disposições aparentemente diferentes pode nos confundir se insistirmos em atribuir um único sentido àquilo com que nos deparamos. Confusão, contradição, espanto... impressões também causadas em pesquisadores, bem no início do século $\mathrm{XX}$, quando uma das principais 
discussões travadas na comunidade científica buscava comprovar se o elétron tinha a forma de onda ou de corpúsculo. Concordando com dois grupos opostos, Niels Bohr afirmou, para estranhamento de muitos, que o elétron era onda e corpúsculo ao mesmo tempo, formulando seu "princípio de complementaridade". Porém, educados que fomos a afirmar isso ou aquilo, até a atualidade tem sido bastante difícil nos desvencilharmos do conforto que uma explicação dicotômica oferece.

Todos os dias era a mesma coisa. Dia após dia a fila de mochilas era feita e desfeita, se constituindo enquanto mais um evento que poderia ser tomado como repetitivo, invisível e insignificante no cotidiano escolar. O espanto que me causou essa fila e o mistério que envolve as condições que a tornaram possível, provocaram em mim muita curiosidade. Eu olhava para aquilo com cuidado, como algo do qual eu me encontrava próxima, mas cujos significados me projetavam para longe, uma vez que escritos em linguagem incompreensível para mim.

Uma fila de mochilas no pátio externo da escola é algo microscópico, mas que dispõe de uma enormidade de significados. Essa fila pode nos dizer que, além do plano institucional, as crianças se organizam informadas pelo conhecimento que dispõem acerca do cotidiano da escola, orientadas por suas necessidades e mediadas pela avaliação que fazem disso tudo. Ao se organizarem, o fazem em meio a interações produtoras de uma ordem que carrega em si a possibilidade de ser tomada enquanto desordem por quem se encontra alheio a esse movimento.

Demarcados os lugares na fila e soado o sinal da entrada, os estudantes debandavam em correria até suas salas, todos os dias, sempre. Por quê? Não havia carteiras para todos? Havia. Estavam atrasados? Não. Precisavam copiar alguma tarefa perdida? Também não. Por que então? Pois quem me falou da correria foi um aluno - em meio a um olhar incrédulo, diante da minha pergunta "óbvia” - a gente corre pra pegar lugar perto dos colegas. Precisei ouvir o que já sabia para lembrar que o havia esquecido: por motivos vários que não comportaria enumerar aqui, os alunos gostam de sentar junto aos amigos na classe. Isso, porém, às vezes se torna a maior das dificuldades, principalmente quando a didática resolve distribuir os alunos na sala de aula utilizando suas "justificativas pedagógicas".

Podemos encontrar nos dicionários que contradição significa incoerência, desacordo, oposição. Essas histórias de meninos provocam em mim uma reflexão quando observo em seus deslocamentos a coerência da contradição, diferente da redundância presente na falta de sentido da contradição posta pela escola. Mesmo trabalhando a favor da educação dos alunos, muitas vezes a escola não se dá conta de que é preciso verificar por onde caminham e tentar ir junto, tentar 
compreender, chegar mais perto.

Em meio à "leitura” do outro e à avaliação de possibilidades, as crianças produzem táticas (CERTEAU, 1994) que lhes permitem mobilidade no espaçotempo que lhes é circunscrito, e que, oficialmente, pouco podem configurar. Agindo de forma tácita e eficaz, reinventam o que está posto, consumindo silenciosamente o que lhes é oferecido a partir de uma lógica própria.

As práticas pedagógicas no cotidiano escolar, bem como as atividades de investigação, em muito podem ser favorecidas quando nos dispomos e perceber e compreender os movimentos das crianças. São movimentos que se dão por meio de interações nem sempre perceptíveis, as quais organizam o espaçotempo de uma forma que a uns remete à noção de ordem e a outros à noção de desordem. Esses movimentos se constituem enquanto táticas frequentemente tácitas, e seu desvelamento pode nos levar a compreender as respostas que as crianças oferecem ao que para elas é posto.

Mediados pela proximidade e envolvimento com seus alunos, muitos professores empregam suas percepções sobre os mesmos ao dinamizarem suas práticas pedagógicas. Nas conversas entre professores podemos encontrar referências a situações inusitadas provocadas por seus alunos as quais, em meio ao estranhamento e surpresa, imprimiram algum direcionamento à aula.

Como as brincadeiras de pular elástico, rodar caderno no dedo, fazer dobraduras e tantas outras se alastram pela escola feito epidemia? Como todo mundo sabe quem está ficando com quem? Como aprendem a oferecer tratamento diferenciado a cada um dos professores? Como descobrem onde ficam as cadernetas, passaportes para a saída? Como sabem o que será servido na merenda? Como sabem que a aula vai acabar cedo antes mesmo da diretora? Como podem rabiscar, rasgar e perder os livros didáticos que estavam ansiosos por receber?

Curioso, isso. No início do ano os estudantes perguntam, diariamente, quando receberão os livros didáticos. Sua insistência pode sinalizar que atribuem valor a esses livros, mas a relação que estabelecem com os mesmos, materializada na depredação, demonstra o contrário. O menino recebe o livro e, junto com ele, uma série de recomendações: não suje, não amasse, não perca, não escreva no livro. Não escreva no livro. Ora... se um livro é um texto com o qual conversamos, e se essa conversa se dá por meio da linguagem escrita, eu preciso escrever no livro. Precisamos. Queremos. Mas não pode... não é permitido sinalizar as diferentes leituras realizadas sobre o mesmo texto, não é permitido desfragmentar as parcelas de conhecimento através de anotações pessoais. O livro didático tão esperado perde a importância, o livro se torna um objeto que fala sozinho, é um monólogo, não tem mais valor.

Por que correm para a fila de merenda se há alimento para todos? Por que 
a cada cinquenta minutos saem das salas de aula se terão que voltar em instantes com a chegada de outro professor? Por que pedem para sair da sala de aula em meio a uma explicação importante? Por que comunicam a falta de um professor se estão contentes com isso? Por que permanecem com os telefones celulares nas mãos se não têm créditos? Por que colam um adesivo nas cadernetas quando se aproxima o dia dos ovos?

Interessante, esse negócio dos ovos. Quando um estudante aniversaria, seus colegas o presenteiam com ovos quebrados na cabeça assim que termina a aula. $\mathrm{O}$ aniversariante é bombardeado e depois vai para casa com a aparência de um quindim. De forma a evitar isso, muitas crianças colam adesivos sobre seus dados pessoais, na primeira página da caderneta escolar, objetivando ocultar a data de nascimento. Passado o aniversário, o adesivo desaparece dali, não há mais riscos. Porém, o próprio adesivo cuja serventia seria ocultar a data natalícia é justamente o que a denuncia, levando o aniversariante a ter frustrada sua tentativa de driblar os colegas ao mesmo tempo em que lhe garante um sorriso feliz entre gemas e claras. Colam adesivos para esconder o aniversário e para anunciá-lo, ao mesmo tempo.

Tudo o que se passa no cotidiano escolar pode ser percebido das mais diferentes formas. As crianças dispõem de lógicas próprias que informam suas percepções, levando-as a interagirem, se organizarem e delimitarem uma espécie de ordem - uma ordem tácita, pois sobre ela não se fala; uma ordem sobre a qual há consenso, pois dela ninguém discorda. Nisso consiste a organização dos estudantes no cotidiano escolar: movimentos rápidos, silenciosos e muitas vezes carregados de contradições ao observador externo.

E esse observador externo, quem é? Esse observador externo é alguém que está dentro da escola, diariamente. É alguém que convive com os estudantes, que transita por ali cheio de boas intenções e cuja racionalidade é outra. Responsável por garantir que as atividades escolares transcorram ordenadamente, compartilha disposições favoráveis às crianças - embora não perceba que estas disposições caminham em sua contramão.

O cotidiano escolar é perpassado por fatores que afetam todas as escolas - os desdobramentos da política neoliberal, as desigualdades sociais, a instabilidade da economia na atualidade. Facilmente percebidos na sociedade, estes fatores nem sempre são discutidos na escola, haja vista as diversas traduções e manifestações com que se revestem ao se instalarem em meio às questões escolares. Não é explícita, por exemplo, a desqualificação docente presente nos cursos de formação continuada, nem tampouco a desconsideração acerca do posicionamento das classes populares durante as reuniões que objetivam a gestão participativa. Geralmente os professores não percebem que as questões que afetam amplamente a sociedade também interferem na escola, assim como 
as práticas que ocorrem nesse espaço também são, geralmente, desconhecidas por quem elabora as normatizações que devem gerir o lugar (PARO, 2001).

Em se tratando da especificidade de cada escola, podemos considerar que aí reside uma certa privacidade da miniatura - privacidade no sentido de permanecer desconhecida e preservada em sua condição de anonimato, por não ser legitimada, por ser considerada menor. As escolas são bastante conhecidas a partir de sua estrutura, e muito pouco pelas transformações ali operadas a partir da inserção externa do que se passa no mundo, e da inserção interna do que se processa em seu cotidiano. É preciso mergulhar na privacidade da miniatura para conhecer a escola, aproximar do quase insignificante, daquilo que se repete... um mergulho dentro do que é pequeno sem o medo de rompê-lo, até mesmo porque não irá se romper, pois não somos tão grandes quanto supomos.

Muito se sabe sobre as diretrizes que orientam os currículos, e pouco sobre os "currículos praticados" (OLIVEIRA, 2003). As normas que regem o funcionamento das escolas são facilmente apreendidas, mas o conhecimento sobre a tradução deste funcionamento em meio às práticas cotidianas é algo que, muitas vezes, se reduz somente aos praticantes. Os resultados da avaliação classificam alunos, escolas e professores, porém a apropriação do conhecimento ainda permanece inacessível a muitos. Parece que a escola dispõe da vocação por ser vista naquilo que deveria ser, enquanto em seu interior se processa silenciosamente aquilo em que ela se transforma a cada dia.

Ainda de forma incipiente, atualmente as pesquisas em cotidiano escolar têm registrado estes movimentos pouco conhecidos e documentados. Trata-se de pesquisas em cotidiano e não sobre ele, investigações interessadas em compreender o que a escola quer dizer e não em buscar respostas para perguntas prescritas. Pesquisas interessadas nos praticantes, em suas conversas, em seus silêncios, em suas rotas aparentemente desconexas - pesquisas que não buscam horizontalizar métodos verticais trocando um caminho por outro. Pesquisas que não comportam métodos lineares, pois sabem que os eventos produzidos em cotidiano escolar ocorrem a partir de repetições diferenciadas em um espaçotempo marcado pela imprevisibilidade.

\section{Conclusão}

Uma fila de mochilas no pátio externo da escola pode ser vista como um amontoado de objetos, ou pode não ser vista, ou pode ser ouvida naquilo que diz. Ali reside uma contradição se tomarmos a relação que os estudantes estabelecem 
com seus pertences no interior da escola, contradição que convida a pensar sobre suas percepções em relação à instituição. Ao depositarem suas mochilas no pátio da escola, os estudantes fazem referência à confiança e camaradagem que se estabelece entre eles quando se encontram ali, entregues a si mesmos.

Entrelaçados à regularidade com que a escola transita em sua trajetória linear, uma pluralidade de deslocamentos microscópicos vai se processando silenciosa e continuamente. Para apreendê-los é preciso se colocar em movimento, aprender sua linguagem, mergulhar em sua privacidade. A explicação definitiva sobre o que seria uma escola não pode ser encontrada no residual, mas pode ser complementada ali, pode ser compreendida de outra forma, bem ali.

Diferente das ciências duras, não é preciso equipamento para observar aspectos microscópicos quando se pesquisa em cotidiano escolar. Não precisamos de instrumentos, precisamos de disposições que nos levem a notar diferença naquilo que se repete, de "lentes" forjadas pelo estranhamento, curiosidade e surpresa. Junto a isso, a insistência - chegar perto, olhar sentindo, ouvir sentindo, tatear, quase tocar... e às vezes perder. Perder, contudo, não significa suprimir definitivamente aquilo que se observava, mas sentir que algo escorregou entre os dedos, ou embaraçou suas percepções, ou te confundiu. Por isso, insista, olhe de novo (sentindo), ouça de novo (sentindo), tateie... porque mesmo sabendo que não podemos reproduzir as condições observadas anteriormente, temos a certeza de que elas se mostram todos os dias sob outras formas.

A escola é uma organização, uma unidade dentro de um sistema que, embora apresente aberturas que permitem a flexibilidade, em muito permanece enrijecida e homogeneizadora. Sua distinção reside no detalhe, nos diferentes usos que lhe conferem os praticantes - sejam eles professores, pessoal administrativo, estudantes ou suas famílias. Enquanto o conhecimento sobre o que a escola deveria ser reside nas normatizações universais, o conhecimento sobre o que ela é se processa continuamente por meio das interações, narrativas e intenções de quem participa do cotidiano escolar.

O que se passa no cotidiano escolar é algo que não se mostra à primeira mirada, nem tampouco pode ser generalizado depois de visto. Como diz Foucault, "sua visibilidade é uma armadilha” - armadilha para aqueles que se encontram sob a vigilância do outro, armadilha para quem se dispõe a compreender a escola e se aprisiona naquilo que facilmente se mostra, no que é amplamente visto. 


\section{REFERÊNCIAS}

CERTEAU, Michel de. A invenção do cotidiano. Artes de fazer. Petrópolis: Vozes, 1994.

HEISENBERG, Werner. A parte e o todo: encontros e conversas sobre física, filosofia, religião e política. Rio de Janeiro: Contraponto, 1996.

MORIN, Edgar. Ciência com consciência. Rio de Janeiro: Bertrand Brasil, 1999.

OLIVEIRA, I. B. de. Currículos praticados. Entre a regulação e a emancipação. Rio de Janeiro: DP\&A, 2003.

PARO, Vitor Henrique. Políticas educacionais: considerações sobre o discurso genérico e a abstração da realidade. In: DOURADO, Luiz Fernandes; PARO, Vitor Henrique (Orgs.). Políticas públicas \& educação básica. São Paulo: Xamã, 2001.

Texto recebido em 16 de outubro de 2008.

Texto aprovado em 21 de novembro de 2008. 